\title{
LA DESNATURALIZACIÓN DE LOS CONTRATOS A SUMA ALZADA EN LA LEY DE CONTRATACIONES DEL ESTADO EN EL CASO DE OBRAS
}

\author{
The denaturization of monetary increasing contracts in \\ the Law of Contracts of the State in the case of works
}

Hugo Sologuren Calmet*

Pontificia Universidad Católica del Perú

Recepción: 19/7/2017

Aceptación: 2/10/2017

\section{Resumen}

Mediante el análisis del sistema de contratación a suma alzada regulado en la normativa en contrataciones del Estado, el autor logra dar cuenta del procedimiento de desnaturalización de dicho sistema en la práctica actual, logrando constituir así un sistema de contratación mixto para el alcance del equilibrio económico financiero del contrato estatal.

Palabras clave: Suma alzada; precios unitarios; expediente técnico; desnaturalización del contrato estatal.

\begin{abstract}
Throught the analysis of the monetary increasing of contracting system, regulated in the regulations of contracting of the State, the author succeeds in explaining the process of denaturalization in the current practice of this system, thus achieving to constitute mixed contracting system for the attainment of the economic balance of the state contract.
\end{abstract}

Keywords: Monetary increasing; unit prices; technical file; denaturation of the state contract.

Abogado por la Pontificia Universidad Católica del Perú. Exvocal del Centro de Arbitraje de la Cámara de Comercio de Lima. Abogado especialista en derecho empresarial, administrativo, regulatorio y litigios arbitrales. 


\section{INTRODUCCIÓN}

En el marco de la contratación pública, las entidades contratan bienes, servicios, obras y consultorías de obras; dependiendo de las particularidades del objeto de la contratación, se puede establecer un valor económico fijo o variable.

En la práctica los contratos pueden ser de dos tipos: a suma alzada o a precios unitarios; el primero se da generalmente a un precio fijo e invariable; el segundo que tiene precios independientes y, por lo que realmente se ejecuta, es variable en términos concretos.

En el caso específico de obras, se utiliza la contratación a precios unitarios cuando no se tiene fijada la cantidad exacta de lo que se va a ejecutar; caso contrario, se utiliza la suma alzada que determina un precio único por toda la ejecución de la obra. No obstante en la experiencia constructiva y en la contratación pública, las entidades licitan prácticamente todo por suma alzada; en el caso de obras, del $100 \%$ de procesos de selección más del 70 $\%$ de los mismos está sujeto a la suma alzada.

Esta situación ha presentado un escenario bastante recurrente, que se desarrolla cuando la obra es ejecutada y se advierte que el expediente técnico posee deficiencias, omisiones, defectos o vacíos que impiden la adecuada ejecución de la obra y además determinan que el ejecutor realice actividades que no se encontraban contempladas en el expediente técnico, generándose sobrecostos que las entidades públicas no reconocen al amparo de la suma alzada.

Lo expuesto ha generado una indeterminada cantidad de procesos arbitrales, en los cuales las primeras alegaciones del demandante consisten en el detalle de diversas deficiencias del expediente técnico que le han generado mayores costos en la ejecución de la obra que las entidades se negaron a reconocer y que los obligan a recurrir a un arbitraje para buscar obtener el respeto del principio del equilibro financiero del contrato.

\section{REGULACIÓN DE LOS CONTRATOS DE SUMA ALZADA EN LA LEY DE CONTRATACIONES}

El sistema de contratación de suma alzada se encuentra recogido en la Ley de Contrataciones del Estado vigente, asimismo ha estado presen- 
te en las diversas y predecesoras normas de contratación que ha tenido nuestro país.

Particularmente el Decreto Supremo N. ${ }^{\circ}$ 350-2015-EF, Reglamento de la Ley de Contrataciones del Estado vigente (en adelante, el RLCE) regula el sistema de contratación de suma alzada en su artículo 14, que señala:

1. A suma alzada, aplicable cuando las cantidades, magnitudes y calidades de la prestación estén definidas en las especificaciones técnicas, en los términos de referencia o, en el caso de obras, en los planos, especificaciones técnicas, memoria descriptiva y presupuesto de obra, respectivas. El postor formula su oferta por un monto fijo integral y por un determinado plazo de ejecución, para cumplir con el requerimiento.

Tratándose de obras, el postor formula dicha oferta considerando los trabajos que resulten necesarios para el cumplimiento de la prestación requerida según los planos, especificaciones técnicas, memoria descriptiva, presupuesto de obra que forman parte del expediente técnico, en ese orden de prelación; debiendo presentar para la suscripción del contrato el desagregado de partidas que da origen a la oferta. El mismo orden de prelación se aplica durante la ejecución de la obra.

Tratándose de consultoría de obras, el postor formula su oferta considerando los trabajos necesarios para el cumplimiento de la prestación requerida, según los términos de referencia y el valor referencial, en ese orden de prelación.

No puede emplearse el sistema de contratación a suma alzada en obras de saneamiento y viales.

Cabe señalar que el sistema de contratación de suma alzada es el sistema que tradicionalmente se ha venido usando en la contratación pública.

No obstante el RLCE establece una precisión que no se encontraba en las normas sobre contratación precedentes, la cual consiste en la prohibición de usar este sistema para la contratación de obras referidas a saneamiento $\mathrm{y}$ viales.

La prohibición comentada responde a la experiencia constructiva y a los innumerables procesos arbitrales en los que contratistas han obtenido sendos resultados positivos, en reclamaciones destinadas a desvirtuar la aplicación de este sistema en los casos específicos de obras de saneamiento y viales, que por sus particularidades no pueden ser definidas en un $100 \%$ y que en muchos casos la suma alzada ha jugado en contra de los intereses del Estado. 


\section{EL EXPEDIENTE TÉCNICO Y SU DEBIDA FORMULACIÓN}

Es de pleno conocimiento que el expediente técnico juega un rol fundamental en la ejecución de la obra, pues es la guía de todo el proceso constructivo.

Se define al expediente técnico de obra ${ }^{1}$ como «el conjunto de documentos que comprende: memoria descriptiva, especificaciones técnicas, planos de ejecución de obra, metrados, presupuesto de obra, fecha de determinación del presupuesto de obra, valor referencial, análisis de precios, calendario de avance de obra valorizado, ${ }^{2}$ fórmulas polinómicas y, si el caso lo requiere, estudio de suelos, estudio geológico, de impacto ambiental u otros complementarios».

Como puede apreciarse, el expediente técnico de obra está formado por un conjunto de documentos de ingeniería que definen, principalmente, las características, alcance y la forma de ejecución de una obra, así como las condiciones del terreno en la que esta se ejecutará.

La información que se presenta en el expediente tiene por finalidad poner en conocimiento de los postores sobre los requerimientos de la entidad para la ejecución de la obra y las condiciones del terreno para que puedan realizar adecuadamente sus ofertas.

Debemos tener en cuenta que, en función a lo que se presente en el expediente técnico, es que el posible ejecutor de la obra podrá saber el alcance de la obra y realizar un análisis de los costos, así como de su rentabilidad a fin de decidir sobre su participación en el proceso de selección.

Tan vital es la información contenida en el expediente técnico y en sí su formulación, que sobre lo que contenga éste se podrá tener una obra adecuada o una pésima obra.

Particularmente, la Dirección Técnico Normativa del Organismo Supervisor de Contrataciones del Estado sostiene que los documentos que integran el expediente técnico «se deben interpretar en conjunto ${ }^{3}$ a fin de que se proporcione información suficiente, coherente y técnicamente correc-

\footnotetext{
1 De conformidad con el numeral 24 del Anexo Único del Reglamento, Anexo de Definiciones.

2 De conformidad con el numeral 5 del Anexo Único del Reglamento, Anexo de Definiciones, el Calendario de avance de obra valorizado es «El documento en el que consta la programación valorizada de la ejecución de obra, por periodos determinados en las Bases o en el contrato.»

De conformidad con lo dispuesto por la Opinión N. ${ }^{\circ} 051-2011 / \mathrm{DTN}$.
} 
ta», que permita formular adecuadamente las propuestas y ejecutar la obra en las condiciones requeridas por la entidad y la normativa de la materia.

\subsection{Responsabilidad de la entidad en la formulación del expediente técnico}

La adecuada formulación del expediente técnico de una obra implica que los documentos que lo componen sean elaborados teniendo una real y efectiva intervención en el lugar donde se ejecutará la obra.

Suele suceder que los expedientes se elaboran en oficina y no se realizan los estudios correspondientes o no se hace una evaluación y verificación integral del lugar a intervenir, lo que lógicamente impacta de forma negativa en el desarrollo de la ejecución de la obra. Por ello resulta transcendental la responsabilidad en la formulación del expediente.

A manera de comentario, el Decreto Legislativo $N^{\circ} 1017$, Ley de Constataciones del Estado derogada, establecía en el quinto párrafo del artículo 134 que las entidades eran las responsables de la adecuada formulación del expediente técnico y de evitar en lo posible su reformulación.

Así, el numeral 32.7 del artículo 32 de la Ley $N^{\circ} 30225$, Ley de Contrataciones del Estado vigente (en adelante LCE), establece:

32.7 La responsabilidad por la adecuada formulación del Expediente Técnico o Estudios Definitivos corresponde al proyectista y a la supervisión, de acuerdo al alcance de los respectivos contratos, y la aprobación a la Entidad. De igual modo, la entrega completa de la información que es puesta a disposición de los postores, corresponde a la Entidad.

La norma vigente aclara específicamente que la responsabilidad de la adecuada formulación del expediente recae en el proyectista, profesional (externo) contratado para la elaboración del documento técnico. En el caso de que la misma entidad haya formulado el expediente, por su calidad de proyectista, será la responsable de su adecuada formulación.

4 Artículo 13.- Características técnicas de los bienes, servicios y obras a contratar

(...) En el caso de obras, además, se deberá contar con la disponibilidad física del terreno o lugar donde se ejecutará la misma y con el expediente técnico aprobado, debiendo cumplir con los requisitos establecidos en el Reglamento. La Entidad cautelará su adecuada formulación con el fin de asegurar la calidad técnica y reducir al mínimo la necesidad de su reformulación por errores o deficiencias técnicas que repercutan en el proceso de ejecución de obras. 
Asimismo, se determina que la entidad posee responsabilidad compartida desde el momento en que aprueba el expediente técnico formulado por un tercero.

El escenario ideal es que ante esta imposición de responsabilidad los expedientes técnicos sean adecuadamente formulados y no sean objeto de reformulaciones por deficiencia u omisiones.

\subsection{Deficiencias $u$ omisiones en el expediente técnico}

Una deficiencia ${ }^{5}$ es un defecto o imperfección de algo o alguien. Por su parte, un defecto ${ }^{6}$ implica la carencia de alguna cualidad propia de algo.

El OSCE ha señalado que una deficiencia del expediente técnico puede presentarse cuando los documentos que lo componen no cumplen con definir adecuadamente las características, alcance y la forma de ejecución de la obra, tampoco describe adecuadamente las condiciones del terreno. En otras palabras, se puede identificar una deficiencia en un expediente técnico cuando no presente información suficiente, coherente o técnicamente correcta para determinar el alcance de las prestaciones que se deben ejecutar ${ }^{7}$.

Asimismo dicha entidad ha precisado que si bien la omisión de información en alguno de los documentos que forman parte del expediente técnico, pero detallada en otro (u otros), se podría considerar una deficiencia del expediente técnico — dado que uno o alguno de sus documentos no estaría presentando la información que debería-, dicha falta de información no podría originar la aprobación de una prestación adicional de obra ${ }^{8}$. De lo expuesto, se entiende que la omisión total de información (entiéndase, en todos los documentos que forman parte del expediente técnico), podría generar la aprobación de una prestación adicional de obra.

Según lo expuesto, en los procesos arbitrales que se generan, siempre se tiene presente como un argumento de defensa de la entidad que los postores

5 Según el Diccionario de Lengua Española 21. (en adelante, el DRAE), "deficiencia», en su primera acepción, significa 1. m. Defecto (II Imperfección).

6 Asimismo, el DRAE, "defecto», en su primera acepción, significa «1.m. Carencia de alguna cualidad propia de algo".

7 Opinión $\mathrm{N}^{\circ} 014-2015-\mathrm{DTN}$.

8 Opinión $\mathrm{N}^{\circ}$ 014-2015-DTN. 
pueden presentar consultas y observaciones ${ }^{9}$ sobre la información contenida en el expediente técnico durante el proceso de selección con el objeto de que la Entidad aclare dicha información.

Sin embargo, esto se deja de lado: muchas de las deficiencias y omisiones del expediente técnico solo pueden advertirse durante la ejecución del contrato (obra).

Esta situación constituye una externalidad que acarrea mayores costos difícilmente previsibles, generando reformulaciones, adicionales, ampliaciones de plazos y otros que afectan el presupuesto de la entidad y/o el contratista, que si no son reconocidos rompen el principio del equilibrio económico del contrato.

\section{DEFINICIÓN DE CONTRATOS DE SUMA ALZADA}

Como lo señala el artículo 14 del RLCE, el sistema de suma alzada es aplicable cuando las cantidades, magnitudes y calidades de la prestación estén definida) en el caso de obras, en los planos, especificaciones técnicas, memoria descriptiva y presupuesto de obra, respectivas.

Así se define al contrato a suma alzada como aquel en virtud del cual el constructor o contratista se obliga a aportar los materiales, organización, administración y realización de la totalidad de los trabajos que sean necesarios para la ejecución integra y oportuna del proyecto encomendado por el dueño o propietario de la obra; todo ello a cambio de un precio fijo y predeterminado $^{10}$.

El aspecto característico de este contrato es que se ejecuta la totalidad de la obra a un precio fijo inamovible.

Así el hecho de que el precio de un contrato de construcción sea a suma alzada no tiene ninguna implicancia en la extensión del alcance de las obligaciones del constructor (tales como la de proveer los materiales o la de asegurar la calidad del diseño o el rendimiento de la obra una vez terminada), sino que solo establece que el monto de las utilidades de éste en el negocio será el resultado de restarle al precio la totalidad de los costos y gastos en los

9 A mayor abundamiento, puede revisarse el artículo 28 de la Ley y los artículos 54 y 56 del Reglamento.

10 MOLINA, Carlos y RÍOS, Víctor. Derecho de la construcción. Santiago de Chile: O’Print Impresores, 2016, p. 48. 
que ha incurrido para cumplir con sus obligaciones. Jurídicamente, ello se traduce en que el precio del contrato se mirará como la única contraprestación a las obligaciones contractuales del constructor, con independencia de los costos incurridos para cumplirlas ${ }^{11}$.

En este tipo de contrato, ante la determinación del precio fijo invariable, se tiene como consecuencia que el propietario de la obra se libere de los riesgos de la variación de los costos de la ejecución del proyecto, independientemente de que la oscilación provenga del precio variable de los materiales, insumos, herramientas y costos.

Esto implica dos cuestiones fundamentales:

a. El contratista realiza su oferta que no está sujeta a ajustes en función a la información proporcionada por el propietario de la obra.

b. El deber de información adquiere sustancial importancia, dado que, ante lo entregado por el propietario es que el contratista realizará su oferta $^{12}$.

El segundo aspecto es en buenos términos el elemento constitutivo de la buena fe que importa que las partes atiendan al cumplimiento de sus obligaciones, colaboren en la ejecución de la obra y procuren el mantenimiento de la equivalencia de las prestaciones a cargo de cada una.

Considerando que la oferta se da ante la información brindada, resulta determinante que el contratista cuente con un proyecto completo y definitivo.

En base a la buena fe el contratista asume que el proyecto y sus especificaciones están en un cien por ciento completos y no son ambiguas ${ }^{13}$.

Por ello el contratista asume el riesgo de la ejecución de la obra, empero no asume los riesgos ni los mayores costos que puedan afectar la obra a consecuencia de las modificaciones que se introduzcan al proyecto, ni tampoco deberá asumir los efectos en costo y plazo originados en la falta de claridad, precisión o detalle del proyecto encomendado ${ }^{14}$.

11 SUTHERLAND, Thomas. Condiciones imprevistas en los contratos de construcción a suma alzada y su aplicación al sitio de las obras. Recuperado de http://www.scielo.cl/scielo.php?scrip$\mathrm{t}=$ sci_arttext\&pid=S0718-80722014000100004.

12 Ibidem.

13 MOBLEY, Thomas. Fundamental of Consortion Law. 2. ${ }^{a}$ división. ABA Forum on The Constrution Industry. 2001.

14 MOLINA, Carlos y RÍOS, Víctor, Ob. cit., p. 52. 
En suma, debemos tener en cuenta que estos contratos se basan en un monto total que será abonado al contratista por la ejecución de los trabajos que estén contemplados dentro del juego de documentos de la licitación $^{15}$, es decir, los planos, memoria descriptiva, estudios de suelos, topografía y especificaciones técnicas, por lo que, «(...) la mínima desviación en la extensión del proyecto incluida en dichos documentos, salvo que sea corregida después en otras cláusulas del contrato, cambiará la extensión; $(\ldots))^{16}$.

De lo señalado, se tiene que estos contratos son mayormente usados cuando existe suficiente información acerca del proyecto, es decir cuando cuentan con los planos, las especificaciones y las memorias técnicas completas, lo cual permite al contratista realizar ofertas bastante cercanas a la realidad; es decir, principalmente se emplean de la mano de concursos de licitación competitivos ${ }^{17}$.

De la regulación establecida en el RLCE se concluye de forma lógica que el presupuesto de aplicación de la contratación a suma alzada es que se cumpla con tener definido lo que va a ser ejecutado, aquí reside su naturaleza.

\section{EL TRATAMIENTO DEL CONTRATO A SUMA ALZADA EN EL CÓDIGO CIVIL. MENCIÓN REFERENCIAL}

Independientemente de que para el caso de la contratación de obras públicas no es posible la aplicación directa de las normas de derecho privado (Código Civil), a manera referencial queremos traer a colación cómo recoge este cuerpo normativo al contrato de suma alzada en el ámbito civil y que tiene en su naturaleza un parecido sustancial con lo regulado por la LCE y el RLCE.

El Código Civil señala en su artículo 1776, lo siguiente:

Artículo 1776.- El obligado a hacer una obra por ajuste alzado tiene derecho a compensación por las variaciones convenidas por escrito con el comitente, siempre que signifiquen mayor trabajo o aumento en el costo de la obra. El comitente, a su vez, tiene derecho al ajuste compensatorio en caso de que dichas variaciones signifiquen menor trabajo o disminución en el costo de la obra.

15 ECHEVARRÍA, Fernando. Asegurando el valor en proyectos de construcción: Una guía estratégica para la selección y contratación del equipo del proyecto. [Tesis para optar el Título de Ingeniero Civil]. Pontifica Universidad Católica del Perú. Lima. 2007, p. 49.

16 LEVY, S.M. Administración de proyectos de construcción. México D. F.: Mc Graw Hill, 2002, p. 19.

17 Ibidem. 
El Código Civil no define el concepto de «ajuste alzado»; dicho cuerpo normativo usa el término "a suma alzada", que constituye una expresión generalmente aceptada en los usos y costumbres de la rama de la construcción, pero, finalmente, el significado de ambos es exactamente el mismo.

En esta modalidad de contrato, las partes acuerdan establecer una equivalencia invariable, por regla general, entre el valor de la obra terminada (el íntegro del trabajo del contratista concretamente convenido y especificado) y el precio (retribución) pactado.

De esta manera el contratista no puede cobrar ninguna cantidad adicional por todo lo que ejecute con el fin de culminar la obra, sin excepción alguna, y según los alcances contratados de la obra. Así todos los costos incurridos por el contratista son de su exclusiva cuenta y riesgo sin posibilidad de luego realizar una reclamación por este aspecto.

Ahora bien, si se hacen cambios o se realizan actividades que no se encontraban contempladas en la documentación técnica, esto propiamente no responde al contrato de suma alzada.

Como lo señala un sector de la doctrina, «(...) todo aquello que no figura en estas especificaciones y descripciones, o que las exceda o supere, no forma parte de la obra pactada («lo que no está en los planos no está en el mundo») $y$, en consecuencia, no forma parte de las obligaciones del contratista. De lo anterior y de lo estipulado por el artículo 1776 del Código Civil, se desprende que todo trabajo u obra que no estaba comprendida específicamente en el pacto inicial, es como una nueva obra que no estaba pactada $(\ldots){ }^{18}$.

Así queda claro que si lo que se va a ejecutar no se encuentra en la documentación técnica entregada propiamente esto no es parte del contrato de suma alzada y, por tanto, se convierte en una obra nueva.

\section{SOBRE LAS DEFICIENCIAS DEL EXPEDIENTE TÉCNICO. POSICIÓN DE LAS ENTIDADES PÚBLICAS}

Como habíamos señalado de forma precedente, existe una suerte de posición casi generalizada de las entidades públicas sobre el tema de las deficiencias y omisiones del expediente técnico.

18 TOVAR, María del Carmen y FERRERO, Verónica. Código Civil comentado por los 100 mejores especialistas. Lima: Gaceta Jurídica. 2007, p. 225. 
La Dirección Técnico Normativa del Organismo Supervisor de Contrataciones del Estado en la Opinión No $014-2015-D T N$ ha concluido que:

\begin{abstract}
Si bien la omisión de información en alguno de los documentos que forman parte del expediente técnico pero detallada en otro se podría considerar una deficiencia del expediente técnico, solo la omisión total de información, entiéndase, en todos los documentos que forman parte del expediente técnico, podría generar la aprobación de una prestación adicional de obra.

Una deficiencia del expediente técnico podría considerarse un vicio oculto cuando, luego de culminado el contrato de consultoría de obra, se advierten defectos en el expediente técnico que no podían ser apreciados a simple vista o empleando la diligencia ordinaria, y que impiden que la Entidad pueda utilizarlo adecuadamente.
\end{abstract}

Particularmente no estamos en desacuerdo con lo expresado por la DTN; no obstante, la interpretación que han venido realizando las entidades públicas sobre esta opinión y su aplicación a los contratos a suma alzada es una cuestión preocupante.

Tenemos que las entidades públicas han venido sosteniendo que en los contratos a suma alzada no existe forma de que las deficiencias $\mathrm{u}$ omisiones generen mayores costos que deben ser reconocidos por éstas.

Tal es el caso que ha sido común escuchar o leer el argumento que la deficiencia u omisión sostenida por un contratista no era tal ya que la información contemplada en un determinado documento del expediente técnico subsanaba la observación realizada, no obstante, cuando se revisa con detenimiento este documento señalado por la Entidad Pública vemos que no existe propiamente una complementación de la información sino que por el contrario se evidencia una incompatibilidad.

Ante esta situación se generan dos posibles opciones:

1. El contratista evalúa la incompatibilidad y propone una solución técnica, que en muchos casos implica realizar actividades adicionales que no se encuentran contempladas en el expediente técnico (como un todo).

2. La entidad persiste en su posición y se genera una controversia que resulta en un proceso arbitral; en éste, ante la reiteración de la decisión de la Entidad sobre este punto se produce, en muchos casos, la imposibilidad de la continuación de la ejecución de la obra.

Con relación a la opción 1 , la entidad no suele aceptarla, debido a que el contrato es a suma alzada y, por tanto, no corresponde reconocer al contra- 
tista ningún concepto remunerativo adicional porque todo está considerado en el precio fijo establecido.

Es por ello que en la mayoría de casos se da la opción 2, y todo termina ante un Tribunal Arbitral que finalmente dirime, ante el adecuado sustento técnico, que debe considerarse y aplicarse la opción 1.

\section{DESNATURALIZACIÓN DE LOS CONTRATOS DE SUMA ALZADA}

Hasta aquí hemos llegado a una conclusión que cae de madura, la suma alzada solo aplica para aquello que está debidamente determinado (definido).

La sola deficiencia y omisión (ausencia total) en un expediente técnico determina per se la inaplicabilidad de la suma alzada. Aun cuando esta omisión puede incluso deberse por vicios ocultos o factores no imputables al proyectista.

En tal sentido, no podríamos hablar de un contrato a suma alzada y estaríamos ante una desnaturalización del mismo.

La Real Academia Española define a la palabra desnaturalizar como alterar las propiedades o condiciones de algo, desvirtuarlo ${ }^{19}$.

Recordemos que la principal característica del contrato a suma alzada es la definición y determinación de lo que va a ser materia de ejecución en el caso de obras. Si se ha omitido algo en el expediente técnico lógicamente no tenemos definido ni determinado lo que realmente se va a ejecutar.

Por ello no podríamos sostener válidamente que todo lo que sea necesario para la culminación del contrato debe ser asumido por el contratista bajo su cuenta y riesgo sin reconocérsele absolutamente nada.

Cuestión que afecta de forma absoluta el principio del equilibrio económico financiero del contrato.

\section{EL EQUILIBRIO FINANCIERO DEL CONTRATO}

Es definido como una relación establecida por las partes contratantes en el momento de celebrar el contrato, entre un conjunto de derechos del

19 Recuperado de http://dle.rae.es/srv/search?m=30\&w=desnaturalizar. 
cocontratante y un conjunto de obligaciones de este, considerados equivalentes: de ahí el nombre de ecuación (equivalencia-igualdad) ${ }^{20}$.

Un sector de la doctrina sostiene que «esta idea de equilibrio o, como se dice aún, de ecuación financiera del contrato, consiste en considerar el contrato administrativo como un conjunto en el cual los intereses de las partes se condicionan; cuando, en algunas condiciones [...], el equilibrio inicialmente considerado se rompe en detrimento del particular cocontratante, este tiene derecho para que el equilibrio sea restablecido por la administración contratante en forma de una compensación pecuniaria» ${ }^{21}$.

Así, en un contrato de suma alzada, la introducción de variaciones en la obra puede traer como consecuencia ajustes en la retribución, ya sea que estos ajustes signifiquen un pago a favor del contratista, si las variaciones encarecerán la ejecución de la obra, o un ahorro del comitente, si las variaciones abaratarán su ejecución. Si es importante resaltar la importancia que tiene el acuerdo previo y escrito entre las partes sobre las variaciones que ejecutará el contratista. Por lo general, este acuerdo incluye una cotización de las variaciones que serán ejecutadas y regula el impacto económico de la misma con relación a la retribución pactada ${ }^{22}$.

\section{CONSECUENCIAS}

A fin de establecer adecuadamente las consecuencias, debemos recalcar que todo aquello que no está contemplado en la documentación técnica de la obra no es parte de la suma alzada y constituye por sí misma una obra nueva, $y$ tiene su propio tratamiento.

Consideramos que si estamos ante algo que no ha sido considerado en el expediente técnico y no ha sido debidamente definido debe ser reconocido a favor del contratista, en la medida que técnicamente se demuestre que su ejecución resulta indispensable para la finalidad del contrato, esto es para la culminación de la obra y su plena operatividad.

20 MARIENHOFF, Miguel. «Contratos administrativos». Teoría general. En Tratado de Derecho administrativo tomo III-A. Buenos Aires: Abeledo Perrot, 1998, p. 469. En igual sentido, véase ESCOLA, Héctor. Tratado integral de los contratos administrativos. Volumen 1, p. 452.

21 DE LAUBADERE, André e GAUDEMET, Yves. Traité de droit administratif tomo 1. París: LGDJ. 2001, p. 706.

22 TOVAR, María del Carmen y FERRERO, Verónica. Código Civil comentado por los 100 mejores especialistas. Lima: Gaceta Jurídica. 2007, p. 225. 
Es por ello que para efectos de proceder a su reconocimiento y pago dicha acción debería realizarse bajo la modalidad de precios unitarios, a fin de determinar exacta y concretamente lo ejecutado por el contratista.

Ello implicaría que la obra pasaría a tener un esquema de contratación mixto, esto es, de suma alzada por las actividades originales y de precios unitarios por las actividades no consideradas y que son indispensables para alcanzar la finalidad del contrato.

Solo para recordar, el RLCE vigente establece en el numeral 3 de su artículo $14^{23}$ la modalidad mixta de contratación de servicios y obras.

De esta manera, una obra bajo el sistema de contratación de suma alzada quedará desnaturalizada en la medida que las omisiones o deficiencias o defectos impliquen la ejecución de actividades no consideradas y que resultan necesarias.

\section{CONCLUSIONES}

El sistema de suma alzada solo aplica para aquello que está debidamente determinado (definido). Si se pretende ejecutar algo que no se encuentra en la documentación técnica entregada, esto no es parte del contrato de suma alzada y, por tanto, se convierte en una obra nueva.

La sola deficiencia y omisión (ausencia total) en un expediente técnico determina per se la inaplicabilidad de la suma alzada. Aun cuando esta omisión puede incluso deberse por vicios ocultos o factores no imputables al proyectista.

Como consecuencia de la desnaturalización del contrato a suma alzada se debe reconocer y pagar a favor del contratista lo que realmente deba ser

23 Artículo 14.- Sistema de Contratación. Las contrataciones pueden contemplar alguno de los siguientes sistemas de contratación: (...)

3. Esquema mixto de suma alzada y precios unitarios, aplicable para la contratación de servicios en general y obras.

Tratándose de servicios, cuando las prestaciones comprendan magnitudes o cantidades que pueden conocerse con exactitud y precisión, se contratan bajo el sistema de suma alzada; los elementos cuyas magnitudes o cantidades no puedan conocerse, se contratan bajo el sistema de precios unitarios.

En el caso de obras, cuando en el expediente técnico uno o varios componentes técnicos corresponden a magnitudes y cantidades no definidas con precisión, se contratan bajo el sistema de precios unitarios, en tanto los componentes, cuyas cantidades y magnitudes estén definidas en el expediente técnico, se contratan bajo el sistema de suma alzada. 
ejecutado y sea necesario para culminar con la ejecución de la obra, en base a precios unitarios, lo que en la práctica configuraría un esquema mixto de contratación.

El reconocimiento de la desnaturalización de la suma alzada conllevará al reforzamiento del principio del equilibrio financiero del contrato y permitirá alcanzar una armonía en la contratación pública. 